\title{
Testing the Epi-No birth trainer where episiotomy is not practiced
}

\author{
Judy Slome Cohain ${ }^{1}$
}

Published online: 8 October 2015

(C) The International Urogynecological Association 2015

The recent review of the Epi-No birth trainer [1] cannot be used to draw conclusions about the usefulness of Epi-No because the reviewed research studies took place where episiotomy is still practiced. The protocols used in such settings do not conform to those proven to optimize outcomes. The adoption of any new therapy should be based on research using scientific methodology adhering to evidence-based protocols.

Between 1940 and 1990, in most high-income countries, $100 \%$ of women having their first child vaginally in a hospital underwent episiotomy. Episiotomy became obsolete in 1983 with the publication of a review of the previous 120 years of use of episiotomy which concluded that episiotomy results in more bleeding, perineal damage, third and fourth degree tears, pain, and incontinence of feces and urine than no episiotomy [2]. Lacking data to support its use, ACOG recommends that practitioners base their decision to perform an episiotomy on 'expert opinion' [3].

The optimal test of Epi-No is to test it in settings where protocols are based on evidence, i.e. where episiotomy is not practiced. Among 80 consecutive primiparous vaginal births delivered by practitioners who never performed episiotomies, $99 \%$ were delivered without the need for suturing [4]. In settings where episiotomy is not practiced, using a combination of prenatal practice with Epi-No and slow delivery of the head starting at crowning, almost all primiparous vaginal births can be delivered without the need for suturing. Where episiotomy is still practiced, it is challenging to identify the benefits of Epi-No.

Conflicts of Interest None.

\section{References}

1. Brito LG, Ferreira CH, Duarte G, Nogueira AA, Marcolin AC (2015) Antepartum use of Epi-No birth trainer for preventing perineal trauma: systematic review. Int Urogynecol J 26(10)1429-1436

2. Thacker SB, Banta HD (1983) Benefits and risks of episiotomy: an interpretative review of the English language literature, 1860-1980. Obstet Gynecol Surv 38(6):322-338

3. American College of Obstetricians-Gynecologists (2006) ACOG Practice Bulletin. Episiotomy. Clinical management guidelines for obstetrician-gynecologists. Number 71, April 2006. Obstet Gynecol 107(4):957-962

4. Cohain JS (2008) Episiotomy: Technology gone haywire: What is the sutured tear rate at first births supposed to be? Int Midwifery Today 85:24-25

An author's reply to this comment is available at doi: $10.1007 / \mathrm{s} 00192-$ 015-2857-8.

Judy Slome Cohain

judyslome@hotmail.com

$1 \quad$ Alon Shvut 37, Israel 90433 